\title{
Modelling the power losses in the ferromagnetic materials
}

\author{
KALina DetKa, KRZYSZTof GóRECKI* \\ Gdynia Maritime University, Department of Marine Electronics, Morska 81 - 87, 81-225 Gdynia, Poland
}

\begin{abstract}
In this paper, the problem of describing power losses in ferromagnetic materials is considered. The limitations of Steinmetz formula are shown and a new analytical description of losses in a considered material is proposed. The correctness of the developed description is demonstrated experimentally by comparing the results of calculation with the catalogue characteristics for different ferromagnetic materials.
\end{abstract}

Keywords: ferromagnetic material; power loss; modelling; powder cores; ferrite cores; nanocrystalline cores

\section{Introduction}

Magnetic materials are commonly used to construct cores of magnetic components, such as inductors and transformers. An important parameter determining the usefulness of these materials in electronics applications is core lossiness, characterized by losses of power in the core during its magnetization [1-5].

Power losses in magnetic materials can be divided into eddy current, hysteresis and residual losses. The share of these components of power losses depends mainly on the type of magnetic material, changes of the peak value of waveform of magnetic flux density and frequency changes $[2,6]$.

Hysteresis losses are typical of powdered materials used in devices in which voltage frequency is in the range of $10 \mathrm{kHz}$ to $1 \mathrm{MHz}$, while eddy current losses are the dominant component of power losses in cores made of metallic materials (amorphous materials, steel sheet) used in devices with low operating frequencies $\mathrm{f}<10 \mathrm{kHz}$ [2]. These losses are generally defined with regard to the unit of weight or volume.

The problem of calculating power losses in ferromagnetic materials frequently appears in the literature [2, 7-9]. The significant influence of flux density amplitude, frequency and temperature on

*E-mail: k.gorecki@we.am.gdynia.pl power losses in a core is given in catalogue data and the problem of formulating the universal dependence describing losses of power in different ferromagnetic materials is pointed out in the literature [8-10].

In this paper the literature models describing the power losses in magnetic materials are discussed and the authors' model of these losses is proposed.

\section{Literature models of power losses in magnetic materials}

In the literature, different models to determine power losses in ferromagnetic materials are proposed. Parchomiuk [8] observed that the total power losses in a toroidal core of a transformer are a sum of hysteresis losses and eddy current losses. The eddy current losses were determined based on the equation:

$$
P_{w}=\frac{\pi}{6} \cdot \sigma_{F} \cdot d^{2} \cdot B_{m}^{2} \cdot f^{2}
$$

where $\sigma_{F}$ is conductivity of material, $B_{m}-$ amplitude of sinusoidal magnetic flux density at frequency $\mathrm{f}, \mathrm{d}$ - sheet thickness.

The author of the cited paper also observed that the expression 1 is valid only for a sine wave of magnetic flux density and suggested inserting a correction coefficient for a rectangular waveform. In turn, to describe hysteresis losses the modified 
Steinmetz equation was proposed. The Steinmetz formula has the form [1]:

$$
P_{v}=k \cdot f^{\alpha} \cdot\left(B_{m}\right)^{\beta}
$$

where $\mathrm{k}, \alpha, \beta$ are material parameters.

Wciślik et al. [10] noted that determination of power losses in a core is difficult due to the fact that occurrence of losses is considered on a microscopic scale, and their description on the macroscopic scale is based on the assumption of homogeneity of magnetic field. In the cited paper, modelling of losses in magnetic materials used in electrical motors was proposed by introducing an equivalent winding including one turn, modelling eddy currents in the magnetic core. It followed from the relation between replacement inductance and resistance that is proportional to magnetic conductivity being a periodic function of rotor rotation angle relative to stator.

The procedure for formulating a general model of power losses in laminated sheets, based on a small amount of data was proposed for frequencies up to $2 \mathrm{kHz}$ by Popescu et al. [11]. This model takes into account hysteresis losses, eddy current losses and residual losses dependent on frequency and amplitude of magnetic flux density which were taken into account by coefficients modifying the Bertotti model in the form:

$$
w_{F e}=B_{m}^{2} \cdot f \cdot\left[k_{h}\left(f, B_{m}\right)+f \cdot k_{e}\left(f, B_{m}\right)\right]
$$

where $\mathrm{k}_{\mathrm{h}}$ and $\mathrm{k}_{\mathrm{e}}$ are material coefficients dependent on frequency $f$ and amplitude of magnetic flux density $B$. The dependences, $k_{h}\left(B_{m}\right), k_{e}(f)$ and $k_{e}\left(B_{m}\right)$ were presented by Goodenough [6], however, the author did not present any description of the dependences $\mathrm{k}_{\mathrm{h}}\left(\mathrm{f}, \mathrm{B}_{\mathrm{m}}\right)$ and $\mathrm{k}_{\mathrm{e}}\left(\mathrm{f}, \mathrm{B}_{\mathrm{m}}\right)$.

Bertotti et al. [9] presented the results of investigation to determine power losses in soft magnetic materials as a result of movement of a single Bloch wall during magnetization of magnetic material. In addition, the well-defined domain structure of the equation was formulated with limited accuracy. The conclusions presented by the authors allow determining the trends of power losses in different ferromagnetic materials.
A model of power losses, called the Olivier model, was proposed by Olivier [12]. The presented model was dedicated for a core made of iron powder material RTP T106-52. The losses in the core were modelled as a sum of hysteresis and eddy current losses. The hysteresis losses were calculated based on the Bozorth model described in the literature [4].

The eddy current losses were calculated as multiplication of material parameters, frequency and amplitude of magnetic flux density. The investigations were conducted in the frequency range of $60 \mathrm{~Hz}$ to $500 \mathrm{kHz}$.

Olivier [12] proposed two different equations describing power losses in the core: for frequency higher than $10 \mathrm{kHz}$ and for frequency lower than $10 \mathrm{kHz}$.

\section{The authors' model of power losses in magnetic materials}

The description of power losses in ferromagnetic materials proposed Górecki et al. [7] by the formula:

$$
\begin{aligned}
P_{v}= & P_{v 0} \cdot f^{\alpha} B_{m}^{\beta} \cdot(2 \cdot \pi)^{\alpha} \\
& \left(1+D \cdot\left(T_{R}-T_{m}\right)^{2}\right) \cdot(0.6336-0.1892 \cdot \ln (\alpha))
\end{aligned}
$$

where $\mathrm{D}$ is a temperature coefficient of the losses in ferromagnetic material, $T_{R}$ - temperature of material $(\mathrm{K}), \mathrm{T}_{\mathrm{m}}$ - temperature at which material losses are the smallest $(\mathrm{K}), \mathrm{P}_{\mathrm{v} 0}$ - material parameter.

The model of losses in ferromagnetic materials defined by the formula 4 is correct in a limited range of frequency and amplitude of flux density.

A significant problem of modelling power losses in ferromagnetic materials using equation 4 was neglecting the influence of temperature and frequency on the material parameters $\left(\mathrm{P}_{\mathrm{v} 0}, \alpha, \beta\right)$. In order to include the influence of temperature, frequency and amplitude of the magnetic flux density on ferromagnetic material properties, an empirical equation describing power losses in ferromagnetic material was formulated. It is expressed by the formula: 


$$
\begin{aligned}
P_{v 0}= & a \cdot \exp \left(-\frac{f+f_{0}}{d \cdot\left(1+d_{1}\left(T_{R}-T_{0}\right)\right)}\right) \\
& +a_{1} \cdot\left(b \cdot\left(T_{R}-T_{m}\right)\right)+c \cdot \exp \left(\frac{f-f_{2}}{f_{1}}\right)
\end{aligned}
$$

where $a, b, c, d, f_{0}, f_{1}, f_{2}$ are the parameters of ferromagnetic material.

For ferrite materials, the parameter $\beta$ occurring in equation 4 depends on temperature and it is expressed by the formula:

$\beta=\max \left(2 \cdot\left(1-\exp \left(-\left(T_{R}-273 K\right) / \alpha_{T}\right)\right)+1.5 ; 1.5\right)$

where $\alpha_{\mathrm{T}}$ is the model parameter. The value of the function $\max (\mathrm{x}, \mathrm{y})$ is equal to a larger value from the arguments $\mathrm{x}$ and $\mathrm{y}$ From equation 6 it is visible that the parameter $\beta$ has the value in the range from 1.5 to 3.5 .

\section{Results}

To verify the correctness of the proposed model of power losses, calculations of characteristics of ferromagnetic cores made of iron powder RTP (-26), ferrite RTF (F867) and nanocrystalline RTN (M-070) were performed. The investigations were conducted for two ambient temperatures equal to $25^{\circ} \mathrm{C}$ and $100{ }^{\circ} \mathrm{C}$. According to Górecki et al. [7], properties of the iron powder and nanocrystaline cores depend very weakly on temperature.

The parameters of the considered magnetic materials are shown in Table 1.

Table 1. Parameters values of the considered magnetic materials.

\begin{tabular}{lccc}
\hline Parameter/material & $(-26)$ & F867 & M070 \\
\hline \hline Magnetic flux density $\mathrm{B}_{\text {sat }}[\mathrm{T}]$ & 1.38 & 0.5 & 1.2 \\
Initial permeability $\mu_{\mathrm{i}}$ & 75 & 2500 & 20000 \\
Curie temperature $\left[{ }^{\circ} \mathrm{C}\right]$ & 750 & 215 & 600 \\
Coercivity field $\mathrm{H}_{\mathrm{c}}[\mathrm{A} / \mathrm{m}]$ & 500 & 75 & 9 \\
\hline
\end{tabular}

The analysis of the data collected in Table 1 shows significant differences of the parameters of considered cores. For example, saturation flux density $\mathrm{B}_{\text {sat }}$ takes the values from $0.5 \mathrm{~T}$ for the ferrite core to $1.38 \mathrm{~T}$ for the iron powder core T106-26.
From the compiled data it can also be seen that the widest hysteresis loop (the largest value of the coercive field) occurs in iron powder materials and the narrowest in nanocrystalline materials.

In turn, the values of parameters occurring in equation 4 to equation 6 are summarized in Table 2.

Table 2. Values of model parameters in equation 4 to equation 6 for three investigated materials.

\begin{tabular}{lccc}
\hline Parameter & \multicolumn{2}{c}{ Value } \\
\hline Material & $(-26)$ & $\mathrm{F} 867$ & $\mathrm{M}-070$ \\
\hline \hline $\mathrm{a}\left[\mathrm{MW} \cdot \mathrm{s}^{\alpha} / \mathrm{T}^{\beta} / \mathrm{m}^{3}\right]$ & 10 & 1.1 & 100 \\
$\mathrm{f}_{0}[\mathrm{~Hz}]$ & $2 \times 10^{3}$ & $2.5 \times 10^{4}$ & 200 \\
$\mathrm{~d}[\mathrm{~Hz}]$ & $1.5 \times 10^{4}$ & $5 \times 10^{4}$ & 10 \\
$\mathrm{~d}_{1}[1 / \mathrm{K}]$ & 0 & 1 & 0 \\
$\mathrm{a}_{1}\left[\mathrm{MW} \cdot \mathrm{s}^{\alpha} / \mathrm{T}^{\beta} / \mathrm{m}^{3}\right]$ & 1.1 & 1.1 & 0.01 \\
$\mathrm{~b}[1 / \mathrm{K}]$ & 0 & 0,013 & 0 \\
$\mathrm{c}\left[\mathrm{MW} \cdot \mathrm{s}^{\alpha} / \mathrm{T}^{\beta} / \mathrm{m}^{3}\right]$ & 12 & 0.7 & $2.8 \times 10^{-8}$ \\
$\mathrm{f}_{2}[\mathrm{~Hz}]$ & 10 & 10 & 10 \\
$\mathrm{f}_{1}[\mathrm{~Hz}]$ & $9 \times 10^{5}$ & $10^{9}$ & $28 \times 10^{4}$ \\
$\mathrm{D}\left[\mathrm{K}{ }^{-2}\right]$ & 0 & $1.1 \times 10^{-4}$ & 0 \\
$\mathrm{~T}_{\mathrm{m}}\left[{ }^{\circ} \mathrm{C}\right]$ & 100 & 80 & 100 \\
\hline
\end{tabular}

The values of these parameters were estimated based on the concept of local estimation described in the literature $[13,14]$.

In Table 3, the values of the Steinmetz model parameters given by the formula 2 are collected.

Table 3. Values of the Steinmetz model parameters.

\begin{tabular}{lccc}
\hline Parameter/material & $(-26)$ & F867 & M-070 \\
\hline \hline $\mathrm{k}\left[\mathrm{W} \cdot \mathrm{s}^{\alpha} / \mathrm{T}^{\beta} / \mathrm{m}^{3}\right]$ & 103 & 10.76 & 2 \\
$\alpha$ & 1.15 & 1.24 & 1.69 \\
$\beta$ & 2.07 & 2.28 & 2.2 \\
\hline
\end{tabular}

Dependences of the $\mathrm{P}_{\mathrm{v} 0}$ parameter on frequency obtained using formula 5 are shown in Fig. 1, for ferrite (Fig. 1a), iron powder (Fig. 1b) and nanocrystalline material (Fig. 1c).

From the presented dependences $\mathrm{P}_{\mathrm{v} 0}(\mathrm{f})$ it can be seen that the highest value of the $\mathrm{P}_{\mathrm{v} 0}$ parameter was obtained for iron powder and the lowest 

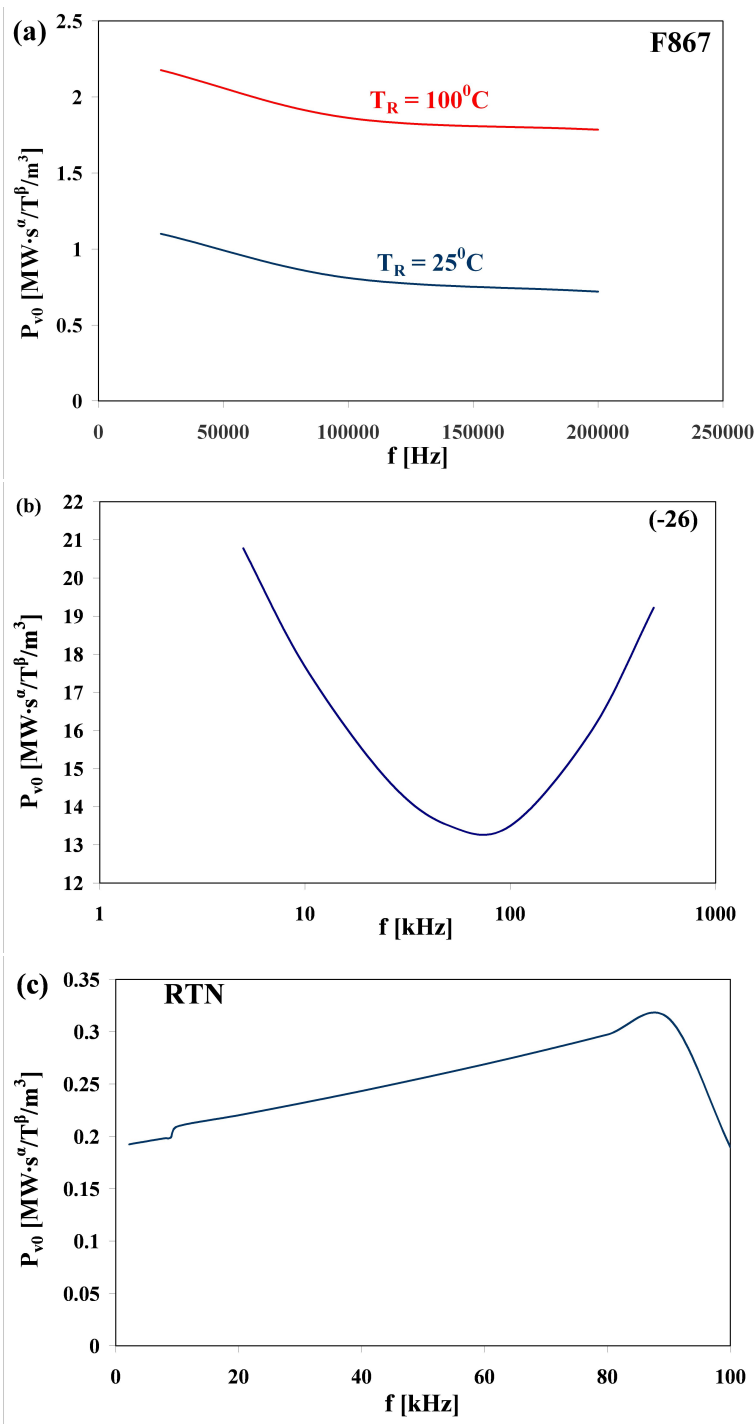

Fig. 1. Dependences of $\mathrm{P}_{v o}$ parameters on frequency for ferrite (a), iron powder (b), nanocrystalline (c) materials.

value of the considered parameter was obtained for nanocrystalline material.

The influence of temperature (Fig. 1) on the value of the parameter $\mathrm{P}_{\mathrm{v} 0}$ for ferrite material was also observed. An increase of temperature from $25{ }^{\circ} \mathrm{C}$ to $100{ }^{\circ} \mathrm{C}$ caused bigger than a double increase in the value of the $\mathrm{P}_{\mathrm{v} 0}$ parameter.

In Fig. 2, the dependence of the $\beta$ parameter on temperature given by formula 6 is presented for F867 material. The value of the parameter $\alpha_{T}$ for this material is equal to $70 \mathrm{~K}$.

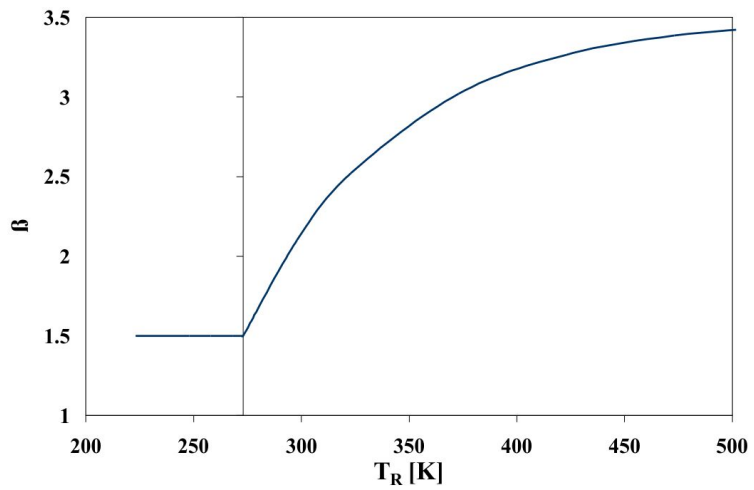

Fig. 2. Dependence of the material parameter $\beta$ on temperature.

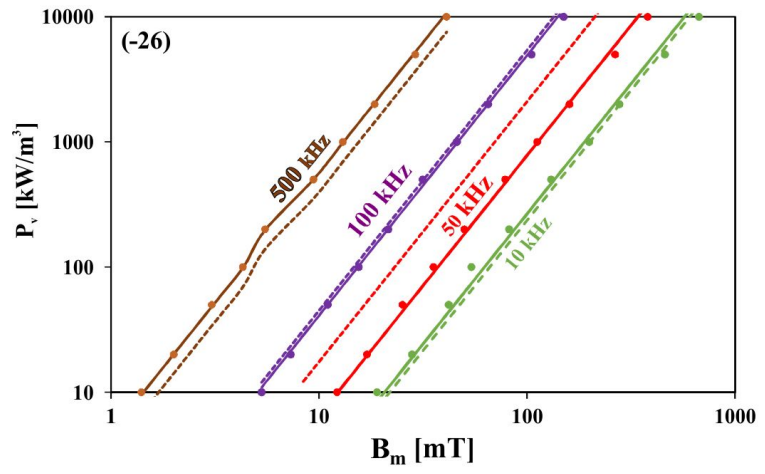

Fig. 3. Dependence of power losses per volume unit in ferromagnetic material (-26) on amplitude of magnetic flux density.

As can be seen, the values of $\beta$ parameter, described by formula 6 , change with temperature. For temperatures lower than $0{ }^{\circ} \mathrm{C}$ this parameter is equal to 1.5 . On the other hand, above $0{ }^{\circ} \mathrm{C}$ it grows with an increase of temperature, achieving the value of about 3.5 at $\mathrm{T}=250{ }^{\circ} \mathrm{C}$.

Fig. 3 and Fig. 4 show dependences of power losses per volume unit on amplitude of magnetic flux density, for the iron powder core and the ferrite core, respectively. In all the figures presented in this section, points denote the results of the catalogue data, solid lines - the results of calculations obtained by the proposed formulas (Fig. 4 to Fig. 6), and dashed lines - the results of calculations using the classical formula 2 .

As can be seen, the modified description of power losses of a ferromagnetic material 

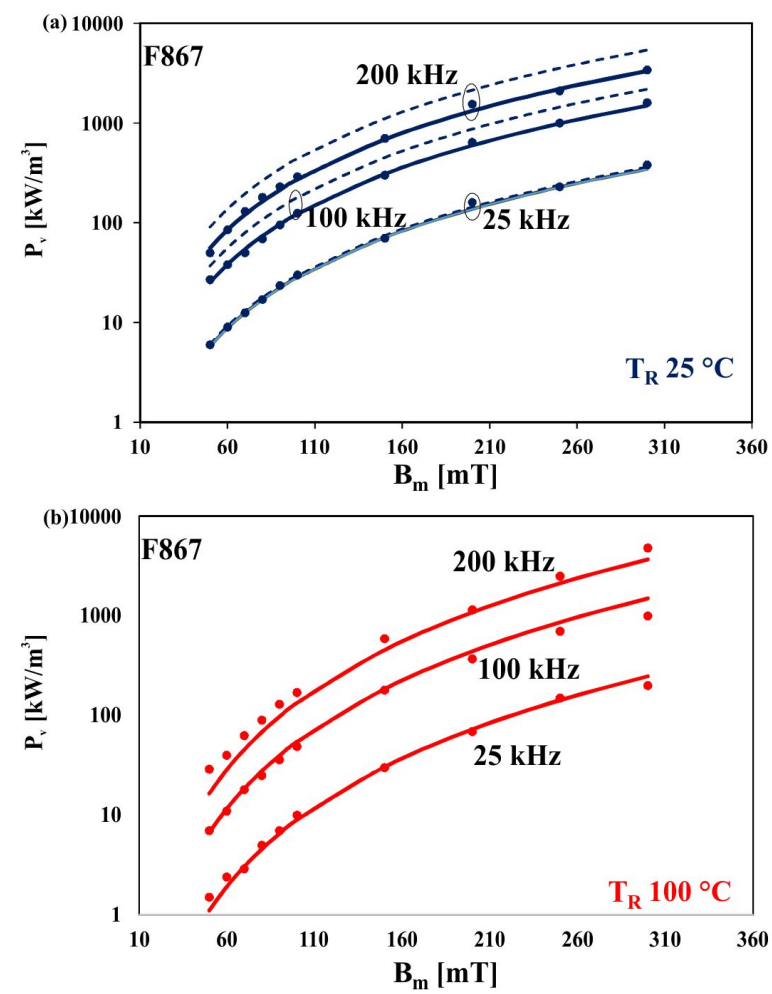

Fig. 4. Dependences of power losses per volume unit in ferromagnetic material F867 on amplitude of magnetic flux density for core temperatures equal to: (a) $25^{\circ} \mathrm{C}$, (b) $100{ }^{\circ} \mathrm{C}$.

significantly improves the convergence between the results of calculations and measurements. The improvement is visible in a wide range of frequency (Fig. 3) and a wide range of temperature (Fig. 4). However, the use of the classical model of power losses can lead to deviations between the results of calculations and measurements which exceed even $50 \%$. It is worth noting that the use of the Steinmetz model does not allow taking into account the influence of temperature on the dependence $\mathrm{P}_{\mathrm{v}}\left(\mathrm{B}_{\mathrm{m}}\right)$.

Fig. 5 and Fig. 6 show dependences of power losses per volume unit on frequency for the cores made of powdered iron (Fig. 5) and nanocrystalline material (Fig. 6).

As it is visible in Fig. 5 and Fig. 6, an increase of frequency of both the considered ferromagnetic materials causes a significant increase of power losses. In addition, the results

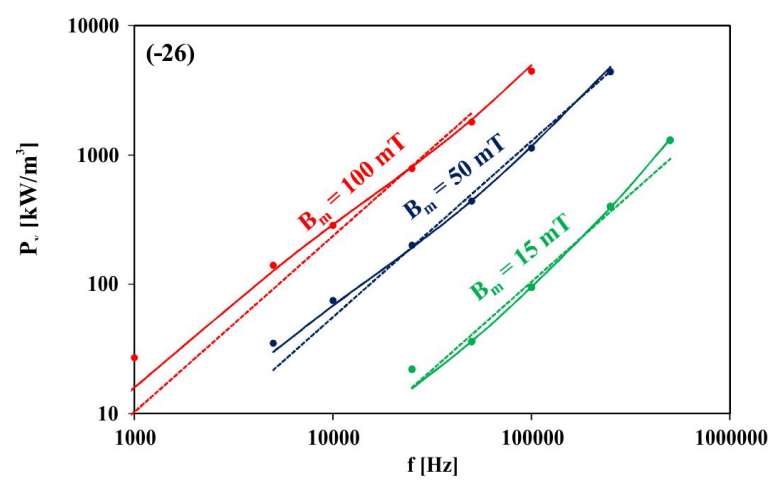

Fig. 5. Dependences of power losses per volume unit in the material $(-26)$ on frequency.

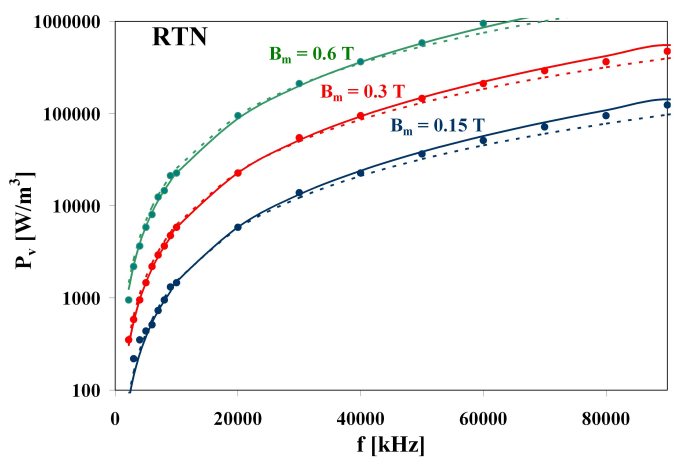

Fig. 6. Dependences of power losses per volume unit in the material M-070 on frequency.

of the modified description of power losses in magnetic materials show a very good agreement with the catalogue data, while the classical model of power losses in the magnetic material causes reduction of power losses even by $20 \%$ for the core made of iron powder and by about $30 \%$ for the core made of nanocrystalline material.

From the presented characteristics $\mathrm{P}_{\mathrm{v}}(\mathrm{f})$, it can be seen that the core made of nanocrystalline material shows up to three times lower value of power losses than the value of power losses obtained for the core made of iron powder. The dependence $\mathrm{P}_{\mathrm{v}}\left(\mathrm{B}_{\mathrm{m}}\right)$ shows that the values of power losses in the core made of iron powder RTP T106-26 are more than 200 times higher than the power losses in the ferrite material at $\mathrm{f}=100 \mathrm{kHz}$.

The dependence of power losses per volume unit in the core made of ferrite material on temperature is shown in Fig. 7. 


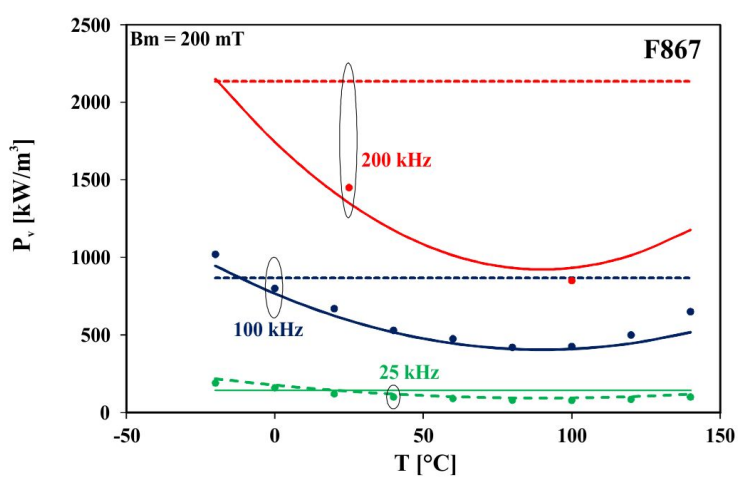

Fig. 7. Dependences of power losses in the ferromagnetic material F867 on temperature.

As it can be seen, the values of power losses in the core made of ferrite material significantly depend on temperature and are higher for higher values of frequency. It is worth noting that the results of calculations obtained using equation 4 to equation 6 are in a good agreement with the catalogue data, while the use of the classical equation 2 causes up to three times overestimation of the value of power losses in the considered ferrite material with an increase of frequency as a result of the neglected influence of temperature on power losses in the magnetic material. Only at frequency equal to $25 \mathrm{kHz}$ the classical Steinmetz dependence allowed obtaining similar results to the Authors' model of power losses in ferrite material. In Fig. 7 of the considered dependence, a local minimum at the temperature of approximately $80^{\circ} \mathrm{C}$ is observed.

Due to the very wide range of changes of the value of power losses in the considered cores, differences between the calculation results obtained using the considered models are barely visible. Therefore, Fig. 8 illustrates the dependence of the calculations error of power losses on frequency and amplitude of flux density. This error is defined by the formula:

$$
\delta P_{V}=\frac{P_{V C}-P_{V M}}{P_{V M}} \cdot 100 \%
$$

where $\mathrm{P}_{\mathrm{VC}}$ denotes the calculated value of $\mathrm{P}_{\mathrm{v}}$ and $\mathrm{P}_{\mathrm{VM}}$ - the measured value of $\mathrm{P}_{\mathrm{v}}$.

In Fig. 8, errors of the calculations based on power losses in ferrite material (Fig. 8a), nanocrys- talline material (Fig. 8b) and iron powder (Fig. 8c) are presented. The curves shown in Fig. 8 denote errors of the calculations of power losses obtained using the equation 2, equation 4 and equation 5 to equation 6 , respectively.
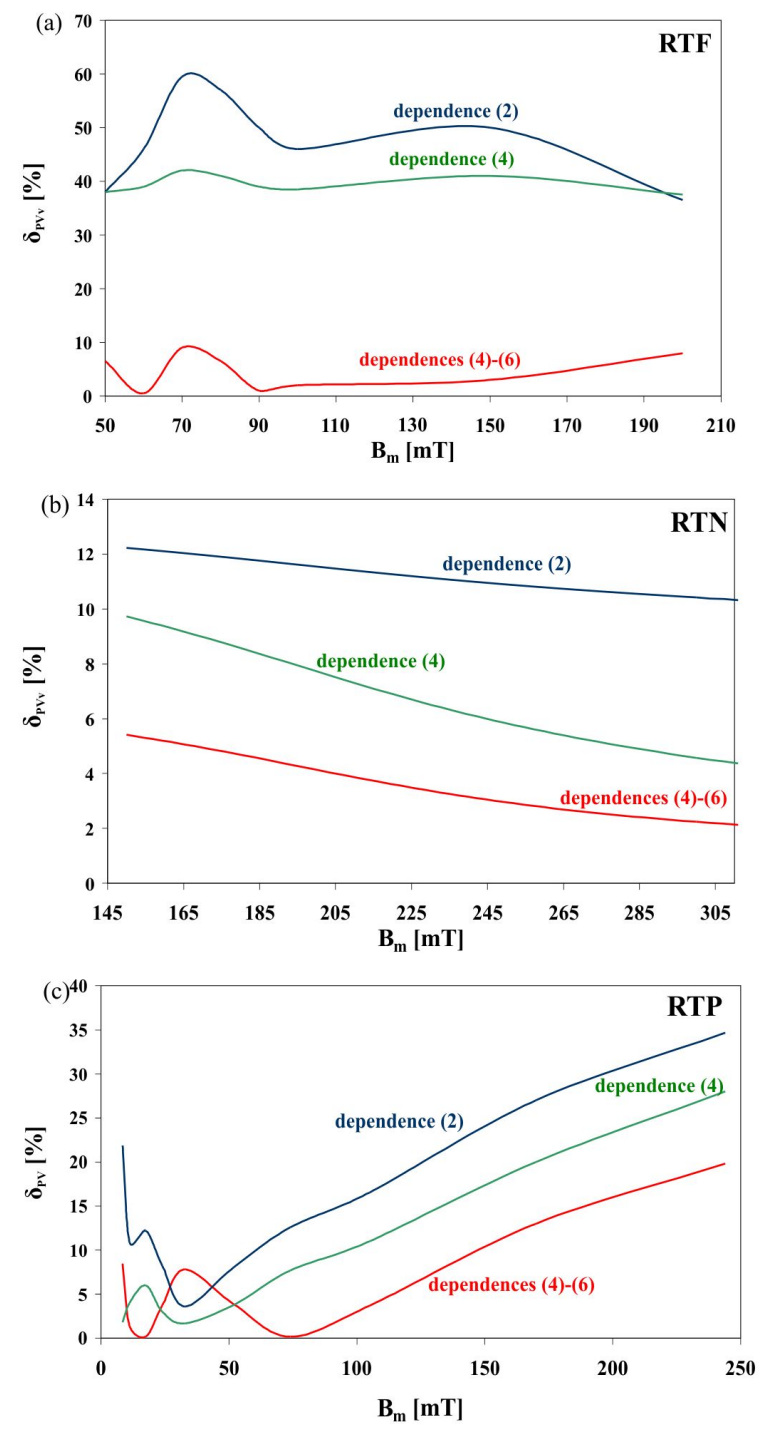

Fig. 8. Dependences of the calculation error of power losses in ferrite (a), nanocrystalline (b), iron powder (c) materials on amplitude of magnetic flux density.

As can be seen, the error of calculations of power losses $\delta_{\mathrm{PV}}$ obtained using equation 4 to equation 6 for all the considered materials has the value even 50 times smaller than the error obtained 
using the classical Steinmetz model described by equation 2. In addition, for a ferrite material, the error obtained using equation 4 with a constant value of parameter $\mathrm{P}_{\mathrm{VO}}$ achieves a similar value to the error obtained using equation 2 in the range of amplitude of the flux density $\mathrm{B}_{\mathrm{m}}$ from 180 to $200 \mathrm{mT}$. Twice higher values of the calculation errors obtained using equation 4 relative to the error obtained with equation 2 at $\mathrm{B}_{\mathrm{m}}=70 \mathrm{mT}$ are observed. It is also worth noting that all the dependences shown in Fig. 8a have the extremum at the same value of amplitude of magnetic flux density equal to about $70 \mathrm{mT}$. The value of the calculation error $\delta_{\mathrm{PV}}$ obtained using the Authors' model for nanocrystalline material is even three times smaller than the value of the error calculated using the classical Steinmetz's dependence. In addition, power losses calculated using the Authors' model for all the considered materials in the range of amplitude of flux density from 50 to approximately $180 \mathrm{mT}$ are at a similar level and do not exceed $10 \%$.

\section{Conclusions}

The paper proposes a new analytical dependence describing power losses in the core made of different ferromagnetic materials. As has been shown, equation 4 to equation 6 , taking into account the influence of frequency and temperature on material parameters, allow obtaining a better agreement between the results of calculations and the catalogue data than by using the classical equations given in the literature.

It is visible that for all of the considered magnetic materials, errors of calculations obtained using the proposed Authors' model described by dependence 4 to dependence 6 did not exceed $10 \%$ in the range of amplitude flux density up to $170 \mathrm{mT}$. Noteworthy is the fact that neglecting the influence of frequency and temperature on the value of $\mathrm{P}_{\mathrm{v} 0}$ in equation 4 and the parameter $\mathrm{k}$ in dependence 2 causes more than double overestimating of power losses in iron powder material, and even twenty times and three times inflated value of the considered power losses in ferrite and nanocrystalline material, respectively.

The description of the presented models of power losses in ferromagnetic cores can be used in the electrothermal model of magnetic elements (inductors and transformers) and contribute to improvement of the accuracy of those models.

\section{References}

[1] Bossche VAn Den A., VAlCheV V.C., Inductors and transformers for power electronics, Taylor \& Francis Group, Florida, 2005.

[2] BARLIK R., NowAK M., Energoelektronika-elementy, podzespoty, uktady (Power electronics: elements and components, systems), Oficyna Wydawnicza Politechniki Warszawskiej, Warsaw, 2014.

[3] Górecki K., DetKA K., Mater. Sci. Eng. B-Adv., 177 (15) (2012), 1248

[4] Bozorth R., Ferromagnetism, D. Van Nostrand Company, Princeton, 1951.

[5] Cullity B.D, Graham C.D., Introduction to magnetism material, John Wiley and Sons, New Jersey, 2011.

[6] Goodenough J.B., IEEE T. Magn., 38 (5) (2002), 3398.

[7] Górecki K., ZaręBSKi J., Detka K., Application of the electrothermal average inductor model for analyses of boost converters, in: NAPIERALSKI A. (Ed.), Proceedings of $22^{\text {nd }}$ International Conference Mixed Design of Integrated Circuits and Systems Mixdes 2015, Lodz, (2015), 417.

[8] PARChOMIUK M., IAPGOS, 4 (2014), 113.

[9] Bertotti G., Fiorillo F., Soardo G., J. Phys. Colloq., 49 (1988).

[10] Wciślik M., Suchenia K., Przeglad Elektrotechniczny, 92 (2) (2016), 152.

[11] Popescu M., Miller T., McGlip M., Ionel D., Dellinger S., Heidemann R., On the Physical Basis of Power Losses in Laminated Steel and Minimum-Effort Modeling in an Industrial Design Environment, in: Conference Record of the 2007 IEEE Industry Applications Conference Forty-Second IAS Annual Meeting, New Orleans, (2007), 60.

[12] Olivier CH., Switch. Power Mag., 3 (2) (2002), 28.

[13] Górecki K., DetKa K, Inform. MIDEM, 45 (1) (2015), 29.

[14] ZaręBSKi J., Górecki K., Int. J. Numer. Model. El., 15 (2) (2002), 181. 